\title{
OPTIMALISASI NILAI THROUGHPUT JARINGAN LABORATORIUM MENGGUNAKAN METODE HIERARCHICAL TOKEN BUCKET (STUDI KASUS: STMIK ASIA MALANG)
}

\author{
Yogie Susdyastama Putra ${ }^{1)}$, Maria Theresia Indriastuti ${ }^{2)}$, Fransiska Sisilia Mukti ${ }^{3)}$ \\ 1), 2),3) Program Studi Teknik Informatika, Fakultas Teknologi dan Desain, Institut Teknologi dan \\ Bisnis Asia Malang \\ Jl. Soekarno - Hatta Jl. Rembuksari No.1 A, Kota Malang, Jawa Timur 65113 \\ Email :yogie@asia.ac.id ${ }^{1}$, maria@asia.ac.id ${ }^{2}$, ${\left.\text { ms.frans@asia.ac.id }{ }^{3}\right)}^{3}$
}

\begin{abstract}
Abstrak
Meluasnya kebutuhan terhadap Internet secara tidak langsung menuntut adanya kestabilan penyediaan akses. Penambahan kapasitas bandwidth tidak selalu menjadi jawaban untuk menjamin ketersediaan layanan ini. Untuk itu, dibutuhkan sebuah prosedur manajemen untuk memaksimalkan bandwidth yang ada, salah satu metode yang dapat digunakan adalah Hierarchical Token Bucket (HTB). Konsep parentchlid melalui penentuan nilai max-limit dan limit-at memberikan jaminan terhadap pemerataan trafik, dengan adanya nilai throughput minimal yang didapatkan oleh user sekalipun berada pada jaringan dengan trafik yang cenderung tinggi. Selain itu, nilai max-limit pada parent memastikan bahwa akumulasi bandwidth yang digunakan oleh child tidak akan melebihi kapasitas bandwidth yang telah ditetapkan pada parent. Implementasi metode HTB yang diaplikasikan pada jaringan laboratorium STMIK Asia Malang berhasil memberikan dampak secara siginifikan terhadap nilai throughput yang dihasilkan, dimana terjadi peningkatan sebesar 1,26 kali lipat lebih baik dibandingkan jaringan non-HTB untuk trafik ringanmenengah (proses streaming) dan peningkatan sebesar 9,27 kali lipat lebih baik dibandingkan jaringan non-HTB untuk trafik berat (proses download).
\end{abstract}

Kata kunci: bandwidth, hierarchical token bucket, optimalisasi, throughput.

\begin{abstract}
The widespread need for the Internet indirectly requires stability in providing access. Increasing the bandwidth capacity is not always the answer to guarantee the availability of this service. For this reason, a management procedure is needed to maximize the available bandwidth, one method that can be used is Hierarchical Token Bucket (HTB). The concept of parent-chlid through the determination of the value of max-limit and limit-at provides guarantees for the equal distribution of traffic, with the existence of a minimum throughput value obtained by the user even though the network tends to have a high traffic. In addition, the max-limit value on the parent ensures that the accumulated bandwidth used by the child will not exceed the bandwidth capacity that has been set on the parent. The implementation of the HTB method applied to the STMIK Asia Malang laboratory network succeeded in providing a significant impact on the value of the resulting throughput, where an increase of 1.26 times was better than the non-HTB network for light-medium traffic (streaming process) and an increase of 9.27 times better than non-HTB networks for heavy traffic (download process).
\end{abstract}

Keywords : bandwidth, hierarchical token bucket, optimization, throughput.

\section{PENDAHULUAN}

Teknologi komunikasi dan jaringan komputer telah berkembang secara eksplosif dalam beberapa dekade terakhir. Berkembangnya jaringan internet bukan lagi sebagai suatu hal yang mewah, melainkan menjadi sebuah kebutuhan di setiap bidang. Tidak dapat dipungkiri bahwa internet memberikan dampak secara signifikan bagi kualitas hidup masyarakat saat ini, baik dampak yang bersifat positif maupun banyak pula dampak negatif yang ditimbulkan dari penggunaan internet yang tidak sesuai pada tempatnya.

Kecepatan akses internet dipengaruhi oleh beberapa hal, antara lain perangkat yang digunakan, topologi yang dipakai, ketepatan administrator jaringan dalam melakukan konfigurasi jaringan, sampai kepada kapasitas bandwidth yang tersedia untuk pengaksesan internet [1]. 
Bandwidth merupakan lebar cakupan frekuensi yang dipakai oleh sinyal dalam medium transmisi, atau biasa disebut sebagai kapasitas maksimum dari suatu jalur komunikasi dalam melakukan transfer data. Jadi, dapat dikatakan bahwa bandwidth berpengaruh cukup signifikan terhadap kecepatan user dalam mengakses Internet [2].

Pada umumnya, penyedia layanan internet (Internet Service Provider/ISP) akan memberikan bandwidth yang berbeda-beda kepada setiap pelanggannya, bergantung kepada jenis kesepakatan yang telah diambil. Semakin besar kapasitas bandwidth yang diterima, maka akan semakin besar juga jalur komunikasi yang dapat dibangun oleh user dalam mengakses internet. Namun, sebesar apapun jalur yang dibangun, tetapi tanpa adanya sistem manajemen yang baik, maka user tetap saja tidak dapat menggunakan akses internet secara efisien. Sistem manajemen bandwidth sangat diperlukan sehingga user bisa mendapatkan hak aksesnya sesuai dengan kebutuhan masing-masing [3][4].

Kampus STMIK Asia Malang merupakan salah satu institusi pendidikan yang memanfaatkan jaringan internet sebagai salah satu perangkat pendukung pembelajaran perkuliahan, baik untuk jaringan berkabel untuk area laboratorium maupun jaringan nirkabel untuk jaringan HotSpot. Terdapat 7 laboratorium yang terbagi menjadi 6 laboratorium di kampus pusat dan 1 laboratorium di kampus 2. Setiap laboratorium terdiri dari 30 buah PC, dimana setiap PC saling terhubung dalam jaringan lokal dan jaringan internet.

Untuk memenuhi kebutuhan ini, STMIK Asia menyediakan bandwidth sebesar 250 Mbps, dengan pembagian 200Mbps untuk kebutuhan kampus pusat dan 50 Mbps untuk kebutuhan kampus 2. Berdasarkan hasil monitoring yang dilakukan oleh tim NOC dari STMIK Asia Malang, akses internet terbesar digunakan oleh laboratorium, khususnya pada jam-jam perkuliahan (mencapai 55\% dari total bandwidth yang disediakan). Padatnya penggunaan internet laboratorium pada jam-jam aktif perkuliahan, secara tidak langsung berdampak terhadap kecepatan akses yang diterima oleh user lain. Hasil di lapangan menunjukkan bahwa tidak didapati adanya pemerataan akses internet yang diterima oleh user. Kegiatan perkuliahan menjadi terganggu ketika user yang memerlukan akses browsing menjadi terhambat oleh karena kapasitas bandwidth banyak terpakai oleh akses user lain yang menggunakan akses internet untuk download dan streaming video.

Berdasarkan akses user yang cukup padat bagi area institusi pendidikan, maka diperlukan adanya manajemen bandwidth yang tepat untuk user, sekaligus memaksimalkan penggunaan bandwidth yang tersedia. Sehingga diharapkan hasil dari penelitian ini dapat memberikan dampak positif bagi divisi terkait untuk meningkatkan efisiensi penggunaan fasilitas internet laboratorium yang telah disediakan oleh pihak institusi kampus.

\section{DASAR TEORI}

\section{a. Bandwidth}

Bandwidth adalah kapasitas atau daya tampung kabel ethernet agar dapat dilewati trafik paket data dalam jumlah tertentu [2]. Bandwidth juga didefinisikan sebagai proses transmisi data dalam suatu jaringan pada waktu tertentu. Satuan bandwidth dinyatakan dengan bit per second (bps). Deretan angka yang terdiri dari 0 dan 1 atau yang dikenal dengan istilah bit atau binary digit. Banyaknya bit (angka 0 dan 1) yang dapat mengalir dari suatu tempat ke tempat lain dalam setiap detiknya melalui suatu media merupakan gambaran dari satuan ini [5]. Bandwidth merupakan konsep pengukuran yang sangat penting dalam jaringan. Secara umum dikelompokkan menjai dua jenis,yaitu up stream dan down stream. Bandwidth up stream merupakan bandwidth yang digunakan untuk mengirimkan data, sementara bandwidth down stream merupakan bandwidth yang digunakan untuk menerima data [6].

\section{b. Hierarchical Token Bucket (HTB)}

Hierarchical Token Bucket (HTB) merupakan salah satu disiplin antrian classfull yang dapat menangani beberapa kasus yang berbeda dengan berbagai jenis lalu lintas. Prosedur penanganan antrian ini dikerjakan pada setiap interface router[2]. Algoritma ini memungkinkan adanya pembuatan antrian secara hirarki (parent and child) dan menentukan hubungan antar 
antrian tersebut. Prosedur yang dilakukan untuk membuat sebuah HTB terbagi menjadi 3 bagian, yaitu [7]:

a. Pencocokan (match) dan menandai (mark) trafik.

b. Pembuatan aturan (policy) untuk proses traffic marking.

c. Pemberian policy untuk interface tertentu

HTB menggunakan konsep token and bucket, yang dikombinasikan dengan sistem berbasis kelas untuk pengendalian trafik. Konsep hirarki yang diterapkan dalam algoritma ini adalah sebagai berikut: children akan meminjam token dari parent sampai mencapai batas bandwidth yang dimiliki parent. Children akan terus mencoba meminjam bandwidth parent sampai nilai threshold yang telah ditentukan pada parent, dan antrian paket akan ditransmisikan kembali apabila token telah tersedia [8].

\section{c. Quality of Service (QoS)}

Quality of Service (QoS) mengacu pada kemampuan jaringan untuk menyediakan layanan yang lebih baik pada trafik jaringan tertentu melalui teknologi yang berbeda-beda[9]. QoS menawarkan kemampuan untuk mendefinisikan atribut-atribut layanan jaringan yang disediakan, baik secara kualitatif maupun kuantitatif. Pada Tabel 1 diperlihatkan nilai presentase dari QoS [10].

Tabel 1. Prosentase dan Nilai QoS

\begin{tabular}{|l|l|l|}
\hline Nilai & Presentase & \multicolumn{1}{c|}{ Indeks } \\
\hline $3,8-4$ & $95-100$ & Sangat memuaskan \\
\hline $3-3,79$ & $75-94,75$ & Memuaskan \\
\hline $2-2,99$ & $50-74,75$ & Kurang memuaskan \\
\hline $1-1,99$ & $25-49,75$ & Buruk \\
\hline
\end{tabular}

Quality of Service (QoS) adalah kemampuan suatu jaringan untuk menyediakan layanan yang baik dengan menyediakan bandwith, mengatasi jitter dan delay. Parameter QoS terdiri dari latency, jitter, packet loss, dan throughput [2].

\section{d. Throughput}

Throughput yaitu kecepatan (rate) transfer data efektif, yang diukur dalam bps (bit per second). Throughput adalah jumlah total kedatangan paket yang sukses yang diamati pada tujuan selama interval waktu tertentu dibagi oleh durasi interval waktu tersebut. Kategori throughput diperlihatkan di Tabel 2 [11].

Tabel 2. Kategori Throughput

\begin{tabular}{|c|c|c|}
\hline Throughput (\%) & Indeks & Kategori \\
\hline $76-100$ & 4 & Sangat baik \\
\hline $51-75$ & 3 & Baik \\
\hline $26-50$ & 2 & Sedang \\
\hline$<25$ & 1 & Buruk \\
\hline
\end{tabular}

\section{METODOLOGI PENELITIAN}

Penelitian ini dikembangkan dengan mengkombinasikan metode eksplorasi, pengamatan, eksperimental serta applied research yang dilakukan secara komprehensif dan bertahap. Secara garis besar, tahapan penelitian yang dikerjakan adalah bersifat kualitatif [5] dengan uraian sebagai berikut:

1. Fase konseptual. Pada tahapan ini, dilakukan proses identifikasi sistem dengan langkah awal melakukan penggambaran terhadap topologi fisik maupun topologi logika yang saat ini digunakan di kampus STMIK Asia Malang. Beberapa hal yang diperhatikan dalam pemahaman sistem ini meliputi pola akses internet oleh user serta waktu penggunaannya. 
2. Fase perancangan. Fase ini merupakan tahapan dalam mendesain parameter dan model penelitian. Hal-hal yang termasuk dalam fase ini antara lain perancangan skenario pengumpulan data penelitian, perancangan konsep solusi yang diberikan untuk penyelesaian masalah, serta skenario pengujian konsep solusi yang diajukan.

3. Fase empirik. Pada fase ini dilakukan pengujian pada studi kasus untuk proses pengambilan data. Data-data yang dikumpulkan pada fase ini mengambil salah satu parameter dari QoS yang telah ditetapkan sebelumnya, yaitu throughput. Nilai ini akan diujikan berdasarkan sampel-sampel pengambilan data di lokasi dalam kurun waktu tertentu.

4. Fase analitik. Fase ini menjadi salah satu proses penting dalam penelitian, yaitu dengan melakukan analisis kinerja sistem berdasarkan data yang didapatkan pada fase empirik. Analisis yang dilakukan meliputi hasil dari manajemen bandwidth yang saat ini digunakan melalui pengambilan sample di beberapa titik pada jam trafik jaringan yang padat maupun pada jam trafik jaringan yang tidak padat, berdasarkan parameter QoS yang telah ditetapkan. Hasil analisis ini nantinya menjadi pedoman dalam menentukan langkah penyelesaian masalah dengan menggunakan metode yang diajukan.

5. Fase diseminasi. Fase ini memberikan hasil dari proses analisis dan penyelesaian masalah yang diajukan oleh peneliti. Dalam hal ini, dengan memberikan rekomendasi sistem manajemen bandwidth menggunakan metode Hierarchical Token Bucket (HTB) dengan mempertimbangkan beberapa faktor, antara lain waktu akses jaringan, pola akses user, dan pembagian penggunaan bandwidth yang disediakan oleh ISP berdasarkan prioritasnya.

\section{HASIL DAN PEMBAHASAN}

a. Lokasi Penelitian

Kampus STMIK Asia Malang memiliki 6 buah laboratorium di kampus pusat dan 1 buah laboratorium di kampus 2. Setiap laboratorium terdiri dari 30 buah PC yang terhubung dalam jaringan lokal (digunakan untuk kebutuhan remote desktop ketika demonstrasi perkuliahan oleh dosen pengampu), dan masing-masing komputer memiliki akses internet. Secara umum, topologi fisik dari jaringan laboratorium yang akan digunakan dalam penelitian ini digambarkan melalui Gambar 1.

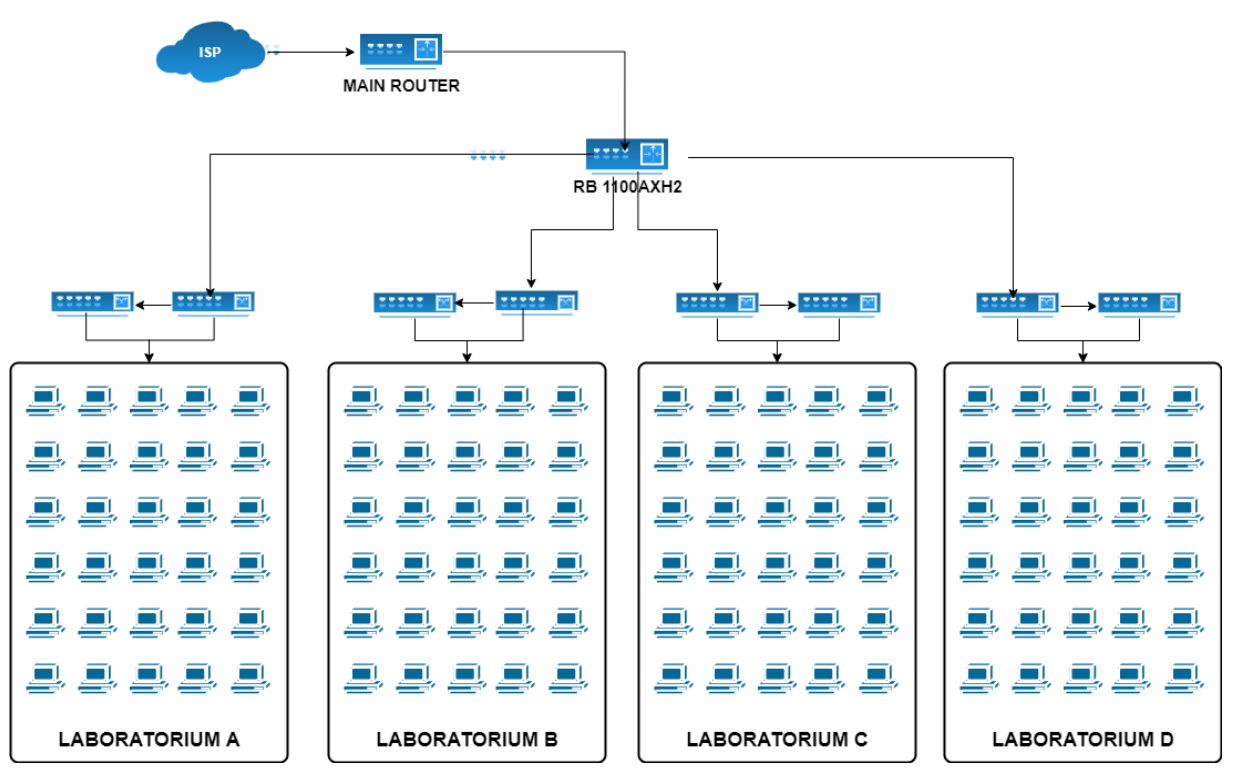

Gambar 1. Topologi Jaringan Laboratorium STMIK Asia Malang

Penelitian diawali dengan melakukan identifikasi secara intensif terhadap layananlayanan yang saat ini digunakan oleh studi kasus. Identifikasi dilakukan secara bertahap dengan proses sebagai berikut : 
1. Sumber distribusi layanan Internet. Secara khusus, akses internet disediakan oleh tim NOC STMIK Asia Malang melalui Router MikroTik RB1100AXH2 yang terhubung ke router utama, yang kemudian didistribusikan melalui 2 buah switch unmanageable 16 port pada setiap laboratorium.

2. Kapasitas bandwidth. Tidak ada pemetaan bandwidth secara khusus yang diberikan oleh tim NOC untuk laboratorium, sehingga bandwidth masih menjadi satu dengan bandwidth utama yang disediakan untuk keseluruhan jaringan.

3. Konfigurasi layanan. Konfigurasi yang diberikan masih bersifat standar, artinya tidak ada pembatasan secara khusus terhadap akses user (dikonfigurasikan hanya sebatas pemberian akses internet untuk keseluruhan user).

4. Pola penggunaan layanan. Pola ini diidentifikasi berdasarkan hasil pemantauan secara intensif terhadap klasifikasi trafik yang paling dominan diakses oleh user pada jam aktif perkuliahan (pukul 07.00 - 19.00).

b. Skenario Pengujian

Proses pengujian yang ditekankan melalui penelitian ini adalah mengadopsi salah satu parameter QoS, yaitu nilai throughput. Nilai ini didapatkan melalui proses monitoring trafik secara real time dengan menggunakan Cacti. Cacti merupakan salah satu aplikasi monitoring jaringan berbasis open-source yang menampilkan hasil monitoring dalam bentuk website. Cacti memanfaatkan fungsional dari Simple Network Management Protocol (SNMP) untuk menangkap data-data utilisasi devais jaringan dan menghasilkan data monitoring berupa grafik data timeseries metrik seperti beban CPU dan pemanfaatan bandwidth jaringan [12]. Prosedur pengujian yang diberlakukan pada penelitian ini adalah sebagai berikut:

1. Sampel pengujian menggunakan 10 user (10 PC) yang tersebar di 4 laboratorium kampus pusat. Pengujian ini dilakukan di luar jam aktif perkuliahan (jam 12.00 - 13.00 dan jam $19.30-20.30)$

2. Proses pengujian dilakukan melalui 2 tahapan, yaitu proses download dan proses streaming. Keduanya dilakukan secara serentak dengan menggunakan server yang sama untuk semua user. Untuk pengujian download, setiap user melakukan download ISO Ubuntu yang diakses melalui https://ubuntu.com/download/desktop , sementara proses streaming dilakukan melalui akses video YouTube (4K Video UltraHD dengan kualitas video 720p).

3. Setiap pengujian dilakukan selama 60 menit, dengan polling interval Cacti setiap 5 menit (didapatkan 12 data per user). Hasil monitoring digambarkan melalui grafik serta dituliskan dalam bentuk nilai throughput (dalam bentuk file csv).

4. Pengujian pertama dilakukan dengan menggunakan kondisi jaringan yang sesungguhnya (digunakan saat ini). Sementara, pengujian kedua dilakukan dengan menerapkan konsep Hierarchical Token Bucket (HTB) pada router distribusi jaringan laboratorium (RB1100AXH2).

5. Pengujian pertama dan kedua menggunakan skema yang sama, yaitu akses download dan streaming yang sama. Hasil monitoring dari kedua pengujian akan dikomparasikan untuk didapatkan hasil analisisnya.

c. Analisa Pengujian

Hasil identifikasi awal yang dilakukan menunjukkan bahwa konfigurasi yang disediakan untuk jaringan laboratorium masih berupa konfigurasi dasar yang belum dikonfigurasikan dengan sistem manajemen bandwidth, sehingga bandwidth yang disediakan oleh ISP digunakan secara penuh tanpa adanya sistem pengendalian. Akibat yang dihasilkan dari sistem ini adalah tidak adanya keseimbangan dalam penggunaan bandwidth, sehingga banyak ditemui ketidakstabilan akses yang dirasakan oleh pengguna, baik ditinjau dari kecepatan akses maupun kestabilan koneksi layanan. Pernyataan ini diperkuat dengan hasil pengujian terhadap nilai throughput yang ditunjukkan melalui Tabel 3. 
Tabel 3. Hasil Pengujian Sistem Saat Ini

\begin{tabular}{|c|c|c|c|c|}
\hline \multirow{2}{*}{ Menit ke - } & \multicolumn{2}{|c|}{ DOWNLOAD } & \multicolumn{2}{c|}{ STREAMING } \\
\cline { 2 - 5 } & MIN (bps) & MAX (bps) & MIN (bps) & MAX (bps) \\
\hline 5 & 84.681 & 5.988 .860 & 708.108 & 1.282 .065 \\
\hline 10 & 73.443 & 6.748 .282 & 687.172 & 1.244 .167 \\
\hline 15 & 50905 & 6881750 & 731.846 & 1.255 .933 \\
\hline 20 & 79.056 & 3.859 .951 & 674.575 & 1.300 .942 \\
\hline 25 & 71.201 & 3.849 .589 & 530.924 & 1.202 .299 \\
\hline 30 & 70.377 & 5.730 .868 & 727.940 & 1.203 .230 \\
\hline 35 & 169.705 & 6.836 .184 & 619.254 & 1.276 .769 \\
\hline 40 & 3.496 & 7.642 .735 & 736.056 & 1.317 .139 \\
\hline 45 & 1.790 & 8.126 .081 & 690.604 & 1.232 .663 \\
\hline 50 & 1.833 & 8.404 .458 & 543.167 & 1.333 .409 \\
\hline 55 & 2.028 & 8.518 .259 & 580.660 & 1.186 .220 \\
\hline 60 & 3.809 & 8.648 .370 & 679.675 & 1.330 .853 \\
\hline
\end{tabular}

Tabel 3 menunjukkan kesimpulan pengujian throughput yang dihasilkan berdasarkan layanan yang digunakan pada studi kasus saat ini. Tertulis nilai MIN (bps) menunjukkan nilai throughput terendah yang didapatkan oleh 10 user, sedangkan nilai MAX (bps) merupakan nilai throughput tertinggi yang didapatkan oleh user. Pengujian sistem melalui proses download yang dilakukan secara serentak oleh 10 sampel user selama 1 jam menunjukkan adanya ketimpangan bandwidth yang diterima oleh user. Sebagai contoh, pada menit ke-45, didapatkan data bahwa user 8 memiliki nilai throughput sebesar 1,7kbps sementara user 6 memiliki throughput yang sangat besar (mencapai 8,1Mbps). Dari contoh ini, dapat kita simpulkan bahwa user akan saling berebut bandwidth, sekalipun mengakses server yang sama. Namun pada pengujian streaming, dapat dilihat bahwa user akan mendapatkan nilai throughput yang cukup stabil, yaitu di atas 500kbps (berpedoman pada nilai minimum throughput yang dihasilkan 530,9kbps).

\section{c. Implementasi Hierarchical Token Bucket (HTB)}

Salah satu cara untuk meningkatkan performa jaringan laboratorium STMIK Asia Malang adalah dengan menerapkan manajemen bandwidth Hierarchical Token Bucket (HTB). Metode ini dipilih berdasarkan pertimbangan studi kasus yang digunakan dalam penelitian ini. HTB menerapkan sistem hirarki dalam manajemen bandwidthnya (konsep parent dan child), sehingga setiap pengguna bisa mendapat kesempatan untuk menggunakan kapasitas bandwidth secara maksimal, sesuai dengan batasan yang diberikan oleh parentnya masing-masing. Skenario konsep HTB yang dilakukan melalui penelitian ini adalah sebagai berikut:

1. Konfigurasi HTB dikombinasikan dengan menggunakan Simple Queue pada MikroTik, dengan kapasitas bandwidth yang disediakan untuk pengujian adalah sebesar 10Mbps. Nilai ini dikonfigurasikan sebagai nilai max-limit parent.

2. Sampel pengujian sebanyak 10 user dijadikan sebagai child dari parent yang telah dikonfigurasikan pada no. 1, dengan konfigurasi sebagai berikut: limit-at 256kbps, maxlimit 2Mbps.

3. Proses monitoring nilai throughput dilakukan melalui Cacti, dengan masa pengujian selama 60 menit, dan polling interval yang digunakan adalah per 5 menit. Hasil monitoring dalam bentuk file csv, untuk kemudian diolah dan dikomparasikan dengan pengujian jaringan non-HTB sebagaimana terangkum pada Tabel 4. 
Tabel 4. Komparasi Pengujian HTB dan Non-HTB

\begin{tabular}{|c|c|c|c|c|c|c|}
\hline \multirow{2}{*}{$\begin{array}{c}\text { Menit } \\
\text { ke- }\end{array}$} & \multicolumn{3}{|c|}{ DOWNLOAD } & \multicolumn{3}{c|}{ STREAMING } \\
\cline { 2 - 7 } & $\begin{array}{c}\text { Hanpa } \\
\text { (bps) }\end{array}$ & $\begin{array}{c}\text { Dengan } \\
\text { HTB } \\
\text { (bps) }\end{array}$ & $\begin{array}{c}\text { Peningkatan } \\
\text { Throughput } \\
\text { (kali lipat) }\end{array}$ & $\begin{array}{c}\text { Tanpa } \\
\text { HTB } \\
\text { (bps) }\end{array}$ & $\begin{array}{c}\text { Dengan } \\
\text { HTB } \\
\text { (bps) }\end{array}$ & $\begin{array}{c}\text { Peningkatan } \\
\text { Throughput } \\
\text { (kali lipat) }\end{array}$ \\
\hline 5 & 84.681 & 445.057 & 5,26 & 708.108 & 826.194 & 1,17 \\
\hline 10 & 73.443 & 443.158 & 6,03 & 687.172 & 851.901 & 1,24 \\
\hline 15 & 50.905 & 482.805 & 9,48 & 731.846 & 826.519 & 1,13 \\
\hline 20 & 79.056 & 453.607 & 5,74 & 674.575 & 782.204 & 1,16 \\
\hline 25 & 71.201 & 494.005 & 6,94 & 530.924 & 812.619 & 1,53 \\
\hline 30 & 70.377 & 446.040 & 6,34 & 727.940 & 826.787 & 1,14 \\
\hline 35 & 169.705 & 480.501 & 2,83 & 619.254 & 838.175 & 1,35 \\
\hline 40 & 3.496 & 473.197 & 135,35 & 736.056 & 797.424 & 1,08 \\
\hline 45 & 1.790 & 476.078 & 265,97 & 690.604 & 841.296 & 1,22 \\
\hline 50 & 1.833 & 507.407 & 276,82 & 543.167 & 825.674 & 1,52 \\
\hline 55 & 2.028 & 490.638 & 241,93 & 580.660 & 858.652 & 1,48 \\
\hline 60 & 3.809 & 481.637 & 126,45 & 679.675 & 888.084 & 1,31 \\
\hline AVG & $\mathbf{5 1 . 0 2 7}$ & $\mathbf{4 7 2 . 8 4 4}$ & $\mathbf{9 , 2 7}$ & $\mathbf{6 5 9 . 1 6 5}$ & $\mathbf{8 3 1 . 2 9 4}$ & $\mathbf{1 , 2 6}$ \\
\hline
\end{tabular}

Tabel 4 menunjukkan komparasi pengujian antara jaringan non-HTB dan jaringan yang menggunakan HTB. Proses pengujian pada jaringan HTB mengadopsi cara yang sama dengan pengujian yang dilakukan pada jaringan non-HTB. Nilai yang ditampilkan pada Tabel 4 merupakan nilai minimal throughput yang didapatkan oleh user dalam satuan bps. Beberapa analisis yang dapat disampaikan melalui implementasi konsep manajemen bandwidth menggunakan HTB antara lain sebagai berikut:

1. Konsep HTB membantu dalam mengontrol bandwidth yang disediakan. Penetapan nilai max-limit pada parent menjadi nilai batasan nilai throughput maksimum yang bisa didapatkan oleh jaringan tersebut (berlaku untuk parent dan child). Konsep ini sangat membantu pihak administrator dalam mengalokasikan bandwidth yang tersedia sehingga dapat digunakan secara maksimal melalui pengelolaan secara terstruktur. Hasil pengujian membuktikan bahwa akumulasi bandwidth yang digunakan selama pengujian tidak lebih dari atau sama dengan 10Mbps, sesuai dengan nilai max-limit yang ditetapkan pada parent.

2. Konsep HTB memberikan jaminan bahwa user akan mendapatkan bandwidth minimal sesuai yang telah ditetapkan. Dalam penelitian ini, ditetapkan nilai throughput minimal setiap user (limit-at) adalah sebesar 256kbps. Terlihat melalui Tabel 4, bahwa selama 60 menit pengujian proses download, didapatkan rata-rata nilai throughput sebesar $472,8 \mathrm{kbps}$. Sementara pada proses pengujian video streaming, didapatkan rata-rata nilai throughput sebesar 659,2kbps.

3. Peningkatan throughput secara signifikan. Hasil pengujian, baik pada proses download ataupun proses streaming, konsep HTB memberikan peningkatan throughput yang lebih baik. Hal ini ditunjukkan dengan melalui nilai rata-rata peningkatan throughput yang dihasilkan pada proses pengujian download mencapai 9,27 kali lipat, sementara pada proses streaming menunjukkan peningkatan sebesar 1,26 kali lipat dibandingkan jaringan tanpa HTB.

\section{KESIMPULAN}

Hierarchical Token Bucket (HTB) merupakan salah satu metode yang dapat diadopsi dalam proses manajemen bandwidth. Adanya konsep parent dan child memastikan bahwa bandwidth yang disediakan dapat dimanfaatkan secara maksimal, tanpa mengganggu atau 
mengambil jatah bandwidth divisi lain. Satu poin penting dalam metode HTB adalah melalui penetapan nilai limit-at yang memberikan jaminan bahwa user akan mendapat nilai throughput minimal sekalipun kondisi trafik jaringan relatif tinggi. Sekalipun tidak ditemui peningkatan secara signifikan pada proses pengujian streaming (nilai throughput yang dihasilkan pada jaringan non-HTB sudah konsisten), namun konsep HTB tetap memberikan nilai throughput 1,26 kali lipat lebih baik dibandingkan jaringan non-HTB. Sebaliknya, metode HTB sangat terlihat dominan pada proses pengujian download, melalui peningkatan nilai throughput yang mencapai 9,27 kali lipat lebih baik dibandingkan jaringan non-HTB. Sebagai kesimpulannya, metode HTB memberikan manajemen bandwidth yang lebih baik untuk tipe trafik ringan-menengah (streaming) maupun untuk tipe trafik yang cenderung tinggi (download), dengan konsep utama menjamin user akan mendapatkan minimal throughput yang telah ditetapkan. Namun, konsep hirarki yang diberikan HTB masih memerlukan ketelitian dari pihak administrator untuk memprediksikan jumlah user yang terdaftar sebagai child, sehingga alokasi bandwidth yang diberikan mencukupi kebutuhan user. Selanjutnya, penelitian bisa dikembangkan untuk proses alokasi bandwidth pada parent secara dinamis dengan melihat jumlah user yang terhubung.

\section{Daftar Pustaka}

[1] G. F. Anastasi, M. Coppola, P. Dazzi, and M. Distefano, "QoS Guarantees for Network Bandwidth in Private Clouds," Procedia - Procedia Comput. Sci., vol. 97, pp. 4-13, 2016, doi: 10.1016/j.procs.2016.08.275.

[2] T. Rahman, "Implementasi Dan Analisis Optimasi Bandwidth Dengan Queue Tree Menggunakan Algoritma Htb Studi Kasus : PT. Sumber Kreasi Fumiko," Paradigma, vol. XIV, no. 2, pp. 141-158, 2012.

[3] G. F. E. Ardiansa, R. Primananda, and M. H. Hanafi, "Manajemen Bandwidth dan Manajemen Pengguna pada Jaringan Wireless Mesh Network dengan Mikrotik," $J$. Pengemb. Teknol. Inf. dan Ilmu Komput., vol. 1, no. 11, pp. 1226-1235, 2017, doi: 10.32736/sisfokom.v4i1.203.

[4] Y. Saniya, W. A. Priyono, and R. Ambarwati, "Sistem Manajemen Bandwidth dengan Prioritas Alamat IP Client," J. Penelit., pp. 1-6, 2013.

[5] S. Budin and I. Riadi, "Traffic Shaping Menggunakan Metode HTB (Hierarchical Token Bucket) pada Jaringan Nirkabel," Bul. Ilm. Sarj. Tek. Elektro, vol. 1, no. 3, p. 144, 2019, doi: 10.12928/biste.v1i3.1100.

[6] I. Riadi, "Optimasi Bandwidth Menggunakan Traffic Shaping," J. Inform., vol. 4, no. 1, pp. 374-382, 2010.

[7] M. Wiki, "Manual HTB," MikroTik Documentation, 2019. https://wiki.mikrotik.com/wiki/Manual:HTB (accessed Feb. 12, 2020).

[8] C. Ben Ameur, E. Mory, and B. Cousin, "Combining Traffic Shaping Methods with Congestion Control Variants for HTTP Adaptive Streaming," Multimed. Syst., vol. 24, no. 1, 2018, doi: 10.1007/s00530-016-0522-9.

[9] A. Wahyu Azinar and R. Sapta Adi, "Analisis QoS (Quality of Service) pada Warnet dengan Metode HTB (Hierarchical Token Bucket)," J. Ilm. Nero, vol. 3, no. 1, pp. 45-52, 2017.

[10] R. Wulandari, "Analisis QoS (Quality of Service) pada Jaringan Internet (Studi Kasus: UPT Loka Uji Teknik Penambangan Jampang Kulon - LIPI)," J. Tek. Inform. dan Sist. Inf., vol. 2, no. 2, pp. 162-172, 2016, doi: 10.28932/jutisi.v2i2.454.

[11] Lisnawita, "Manajemen Bandwidth Menggunakan Metode Hierarchical Token Bucket (HTB)," J. Teknol. Komun. Digit. Zo., vol. 7, no. 1, pp. 18-25, 2016.

[12] The Cacti Group, "Cacti Documentation," The Cacti Group, Inc. https://www.cacti.net/documentation.php (accessed May 28, 2020). 